\title{
ORNL Interim Progress Report on Static CIRFT Testing Curvature Data Update
}

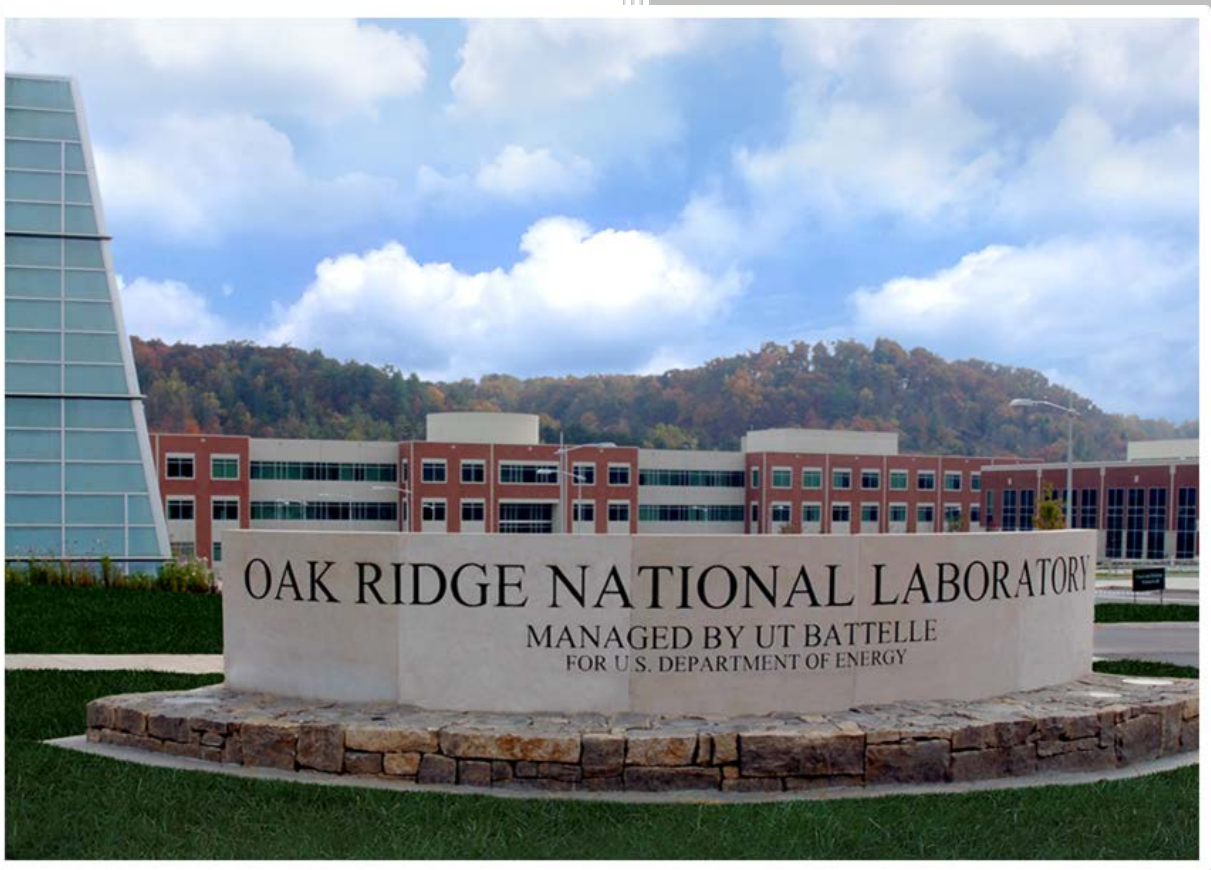

Jy-An John Wang Hong Wang

October 10, 2016 


\title{
DOCUMENT AVAILABILITY
}

Reports produced after January 1, 1996, are generally available free via the U.S. Department of Energy (DOE) Information Bridge.

Web site http://www.osti.gov/bridge

Reports produced before January 1, 1996, may be purchased by members of the public from the following source.

\author{
National Technical Information Service \\ 5285 Port Royal Road \\ Springfield, VA 22161 \\ Telephone 703-605-6000 (1-800-553-6847) \\ TDD 703-487-4639 \\ Fax 703-605-6900 \\ E-mail info@ntis.gov \\ Web site http://www.ntis.gov/support/ordernowabout.htm
}

Reports are available to DOE employees, DOE contractors, Energy Technology Data Exchange (ETDE) representatives, and International Nuclear Information System (INIS) representatives from the following source.

Office of Scientific and Technical Information

P.O. Box 62

Oak Ridge, TN 37831

Telephone 865-576-8401

Fax 865-576-5728

E-mail reports@osti.gov

Web site http://www.osti.gov/contact.html

This report was prepared as an account of work sponsored by an agency of the United States Government. Neither the United States Government nor any agency thereof, nor any of their employees, makes any warranty, express or implied, or assumes any legal liability or responsibility for the accuracy, completeness, or usefulness of any information, apparatus, product, or process disclosed, or represents that its use would not infringe privately owned rights. Reference herein to any specific commercial product, process, or service by trade name, trademark, manufacturer, or otherwise, does not necessarily constitute or imply its endorsement, recommendation, or favoring by the United States Government or any agency thereof. The views and opinions of authors expressed herein do not necessarily state or reflect those of the United States Government or any agency thereof. 
Materials Science and Technology Division

Oak Ridge National Laboratory

\section{ORNL INTERIM PROGRESS REPORT ON STATIC CIRFT TESTING CURVATURE DATA UPDATE}

Jy-An John Wang and Hong Wang

NRC Program Manager: Michelle Bales

ORNL Program Manager: Bruce Bevard

Date Published: October 2016

Prepared by

OAK RIDGE NATIONAL LABORATORY

Oak Ridge, Tennessee 37831-6283

managed by

UT-BATTELLE, LLC

for the

U.S. DEPARTMENT OF ENERGY

under contract DE-AC05-00OR22725 


\section{Contents}

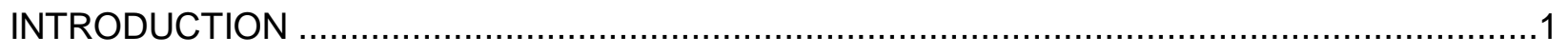

CURVATURE MEASUREMENT AND CORRECTION ................................................

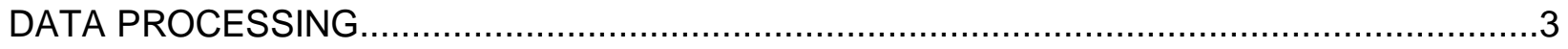

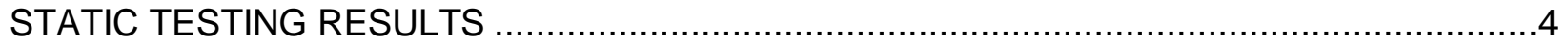

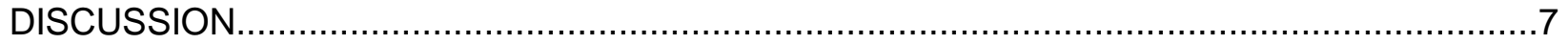

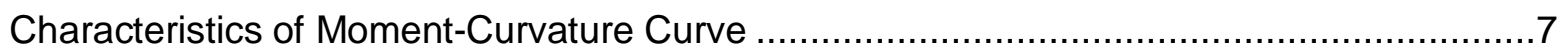

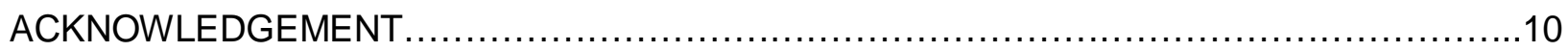

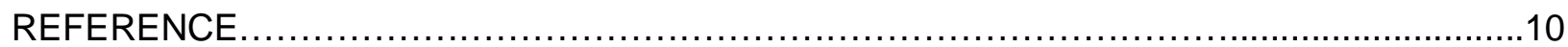

APPENDIX: Moment-Curvature Curves and Equivalent Stress-Strain Curves for Static Tests with

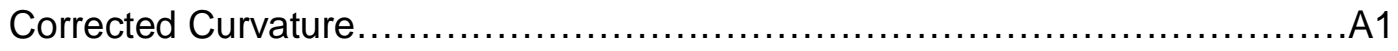




\section{List of Figures}

Figure 1. Determination of the bending curvature of the rod by use of deflections measured at

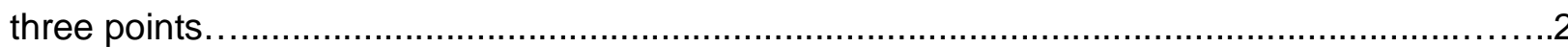

Figure 2. Deflections measured by LVDTs may be at different points from initial positions in (a) positive and (b) negative curvature, and sensor spacing $\mathrm{h}$ needs to be corrected........................

Figure 3. Moment-curvature curves with raw data and de-noised data.................................. 4 Figure 4. (a) Curve of moment versus curvature for S1 (606C3C) with and without correction applied.

Figure 5. (a) Moment -curvature curve, and (b) equivalent strain-stress curve for S1 (606C3C). 6 Figure 6. Curvature-moment curves based on three-LVDT measurements in static tests............7

Figure 7. Characteristic points of curvature-moment curve. .8 


\section{List of Tables}

Table 1. Characteristic points and quantities based on curvature-moment curves.................9

Table 2. Characteristic points and quantities based on equivalent strain-stress curves..........9 


\section{INTRODUCTION}

Since the CIRFT tests reported in NUREG-7198 were generated, a number of factors that influence the recorded curvature measurement data were identified. In 2016, a data reanalysis task was undertaken to implement the lessons learned. This letter report provides the revised results of previous CIRFT tests, after implementing the following data reanalysis procedures: (A) experimental data smoothing and LVDT reset, (B) LVDT probe contact and sensor spacing correction for curvature data, and (C) LVDT probe dynamic vibration adjustment procedure development.

\section{CURVATURE MEASUREMENT AND CORRECTION}

Theoretically, the bending radius and maximum strain of a rod can be estimated on the basis of the traveling displacement at the loading points of the rigid arm. The displacement measured, however, contains the contribution of the compliant layers, depending on the materials used in the compliant layers and the level of loading.

To address this issue, measurement of the specimen displacement at three adjacent points along the rod method was adopted and has been implemented to evaluate the curvature of a bending rod in this study.

Given the deflections from three LVDTs, $d_{1}, d_{2}$, and $d_{3}$, as shown in Figure 1 , the curvature $\kappa$ of the bending rod can be evaluated as follows:

$$
\begin{aligned}
& \kappa=\left[\left(x_{0}-d_{2}\right)^{2}+y_{0}^{2}\right]^{-1 / 2}, \\
& x_{0}=\frac{-2 m_{a} m_{b} h-m_{a}\left(d_{2}+d_{3}\right)+m_{b}\left(d_{1}+d_{2}\right)}{2\left(m_{b}-m_{a}\right)}, \\
& y_{0}=-\frac{1}{m_{a}}\left(x_{0}-\frac{d_{1}+d_{2}}{2}\right)-\frac{h}{2},
\end{aligned}
$$

where

$$
\begin{aligned}
& m_{a}=\frac{h}{d_{2}-d_{1}}, \\
& m_{b}=\frac{h}{d_{3}-d_{2}},
\end{aligned}
$$

and $h$ is the sensor distance, $12 \mathrm{~mm}$. 


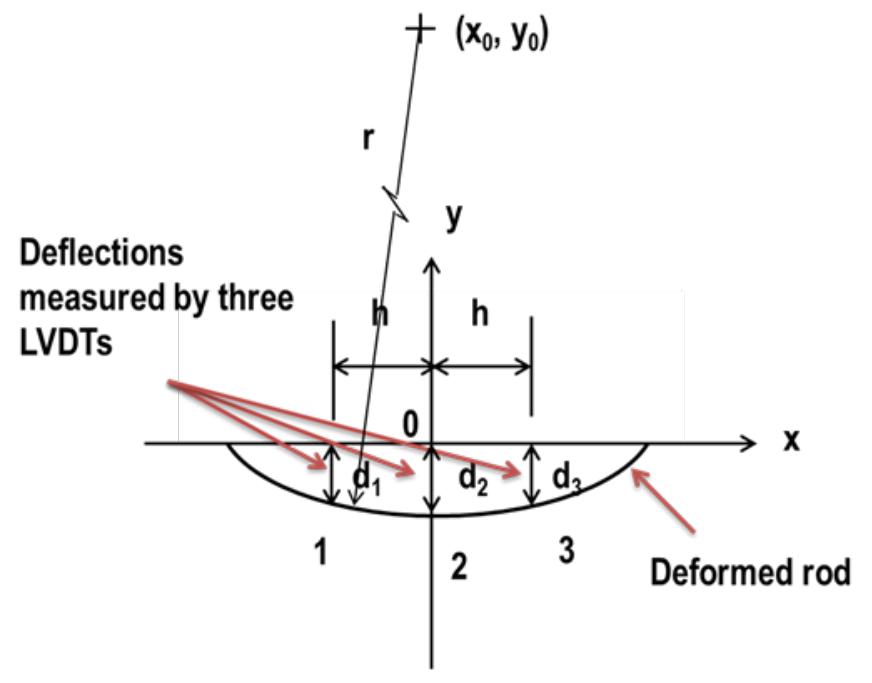

Figure 1. Determination of the bending curvature of the rod by use of deflections measured at three points.

In the cyclic bending test, a disk shaped LVDT probe is used to ensure a reliable contact with the rod for online monitoring. The contact points of LVDTs on the left and right may change as shown in Figure 2, depending on bending direction and induced curvature. This results in the deviation of sensor spacing from the ideal condition.

For positive curvature, actual sensor spacing $h_{2}$ is

$h_{2}=h+\Delta h$

and for negative curvature, actual sensor spacing $h_{1}$ is

$h_{1}=h-\Delta h$

In order to use Eq. (1) in the calculation of curvature, the sensor spacing correction $\Delta \mathrm{h}$ needs to be determined. In this update, an adjustment procedure based on the equal gauge length is introduced. In fact, an effective half-gauge length of the rod, $L_{g} / 2$, can be defined once the deflection $\mathrm{d}_{2}$ and curvature $\kappa$ are given, or

$$
L_{g} / 2=\sqrt{2 d_{2} / \kappa} \text {. }
$$

In the current testing setup, the gauge length is considered the same if the rod is bent in positive or negative direction. By applying the Eq. (3) to the maximum and minimum deflection values, the equality of half-gauge length results in the following relation,

$d_{2 p}^{+} /\left.\kappa_{p}^{+}\right|_{h_{2}=h+\Delta h}=d_{2 p}^{-} /\left.\kappa_{p}^{-}\right|_{h_{1}=h-\Delta h}$. 
The spacing correction $\Delta \mathrm{h}$ can thus be obtained by resolving Eq. (4).

The corrected curvature based on the equal gauge length concept has been demonstrated experimentally to be equal to the curvature based on the moment input and given rigidity; where a polycarbonate rod (11.11 $\mathrm{mm}$ diameter and $152.40 \mathrm{~mm}$ length) was tested under displacement control to $\pm 6 \mathrm{~mm}$ at each loading point of U-frame.

The data analysis is conducted with the probe spacing correction selected as follows:

- In the monotonic test, $\Delta \mathrm{h}=2.50 \mathrm{~mm}$ as suggested by the calibration is used.

- In the reversed cyclic bending test, the $\Delta \mathrm{h}$ is obtained directly using Eq. (4) because the maximum and minimum deflections pair is available in the data block registered from the test time history data.

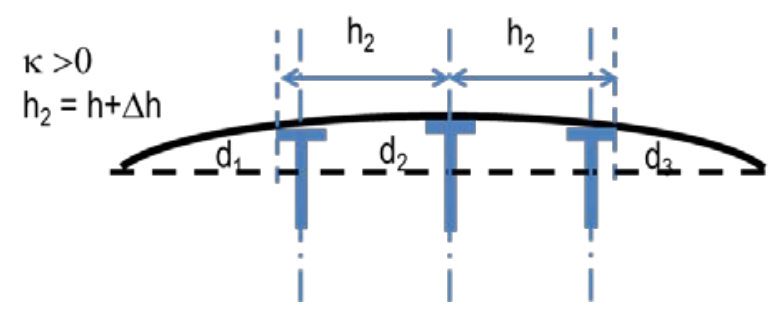

(a)

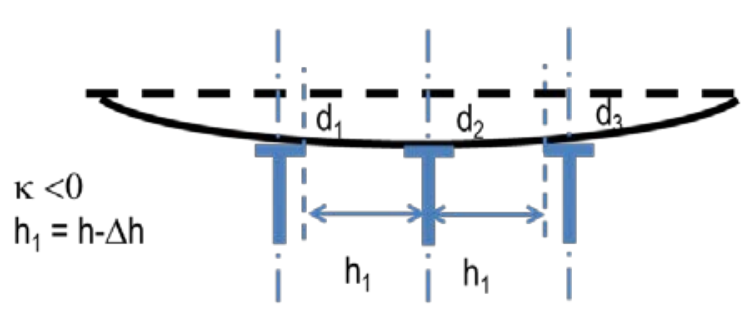

(b)

Figure 2. Deflections measured by LVDTs may be at different points from initial positions in (a) positive and (b) negative curvature, and sensor spacing $h$ needs to be corrected.

\section{DATA PROCESSING}

Measurement data and on-line monitoring data are converted into the applied moment and curvature, based on the load channel (load1 and load2) information, the loading arm length (101.60 mm), and LVDT data (LVDT1, 2, and 3). The moment was estimated by 
$M=F \times L$

where $F$ is the averaged value of applied loads (load1 and load2) from the Bose dual motors, and $L$ is the loading arm length, $101.60 \mathrm{~mm}$. The curvature $\kappa$ was estimated as described above. Raw data are generally very noisy. The noise is removed in the time domain by using a MATLAB curve-fitting function SPAP2; an example of the de-noised moment-curvature curves is shown in Figure 3 in which a cubic 33-piece spline function was used.

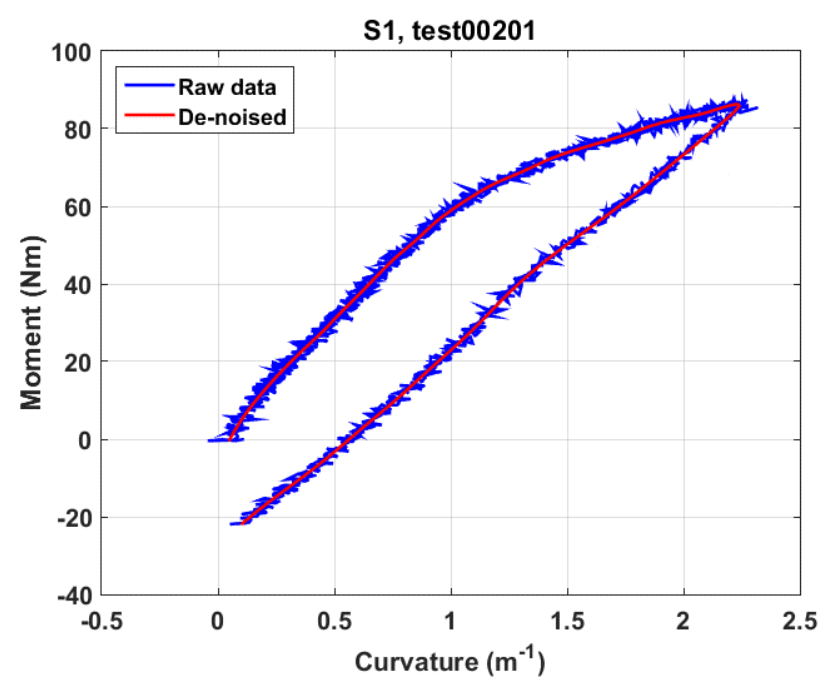

Figure 3. Moment-curvature curves with raw data and de-noised data.

An equivalent strain-stress curve can be obtained under the assumption that the SNF rod can be idealized as a linear elastic homogeneous material without consideration of the effects induced by pellet-clad interaction. The equivalent stress was calculated using:

$\sigma=M \times y_{\max } / I$

where $I$ is the moment of inertia, $I=I_{c}+I_{p}, I_{c}$ and $I_{p}$ are moments of inertia of cladding and pellet, respectively, and $y_{\max }$ is the maximum distance to the neutral axis of the test rod of the section and is measured by the radius of the cladding. And the equivalent strain is given by:

$\varepsilon=\kappa \times y_{\max }$

\section{STATIC TESTING RESULTS}

Four static tests were conducted. 
S1 (606C3C, $66.8 \mathrm{GWd/MTU}$ burnup, 70-100 $\mu \mathrm{m}$ oxide layer) survived four static loading cycles without failure. The moment-curvature curve for the initial cycle is presented in Figure 4 (the curves of subsequent cycles overlay one another to a great extent and for clarity are not plotted). The maximum moment achieved in this loading cycle was $85.5 \mathrm{~N} \cdot \mathrm{m}$. Both the old curvature dat and the corrected curvature data with $2.5 \mathrm{~mm}$ spacing adjustment were provided. in Figure 4 for comparison purpose.

There is a significant effect of probe spacing on the curvature measurement. The maximum curvature was decreased from 3.2 to $2.2 \mathrm{~m}^{-1}$ after the correction was applied. The distinctive slope changes of the moment-curvature curves were observed near 17 and $60 \mathrm{~N} \cdot \mathrm{m}$, respectively. The deflection points indicate that the flexural rigidity might be changed in the SNF rod system. The moment-curvature curve and equivalent stress-strain curve for the initial cycle are presented in Figure 5.

Since the machine capacity was reached and no failure occurred to the specimen, a follow-up dynamic test was conducted under \pm 25.40 to $30.48 \mathrm{~N} \cdot \mathrm{m}$ at $5 \mathrm{~Hz}$ to fracture the specimen for further postmortem examination. The rod failed around $1.4 \times 10^{4}$ cycles.

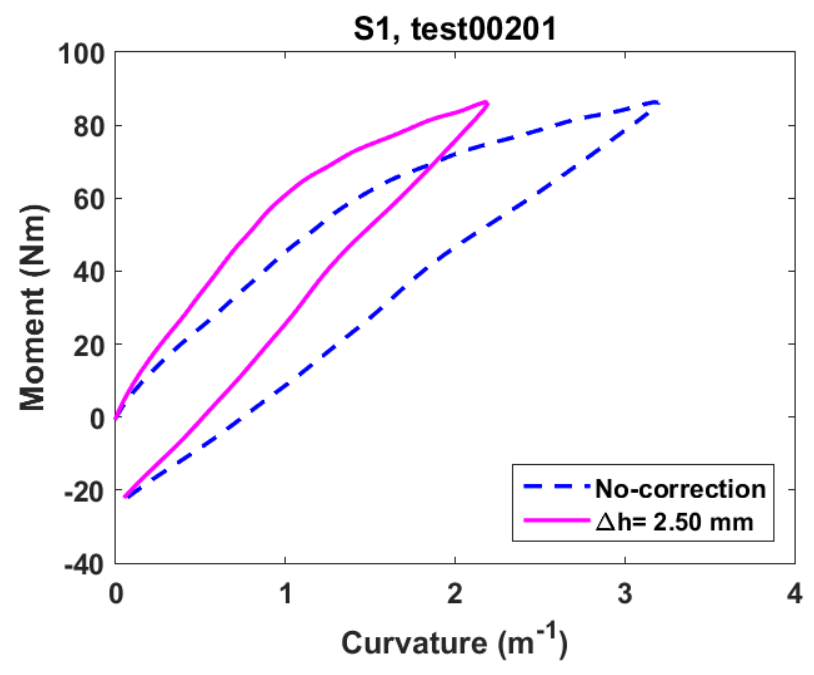

Figure 4. (a) Curve of moment versus curvature for S1 (606C3C) with spacing $2.5 \mathrm{~mm}$ adjustment and without spacing correction applied. Based on a static loading cycle in which the maximum relative displacement was $24 \mathrm{~mm}$ and the rates at the loading points of the $U$ frame were set at 0.1 and $0.2 \mathrm{~mm} / \mathrm{s}$ for loading and unloading, respectively. 


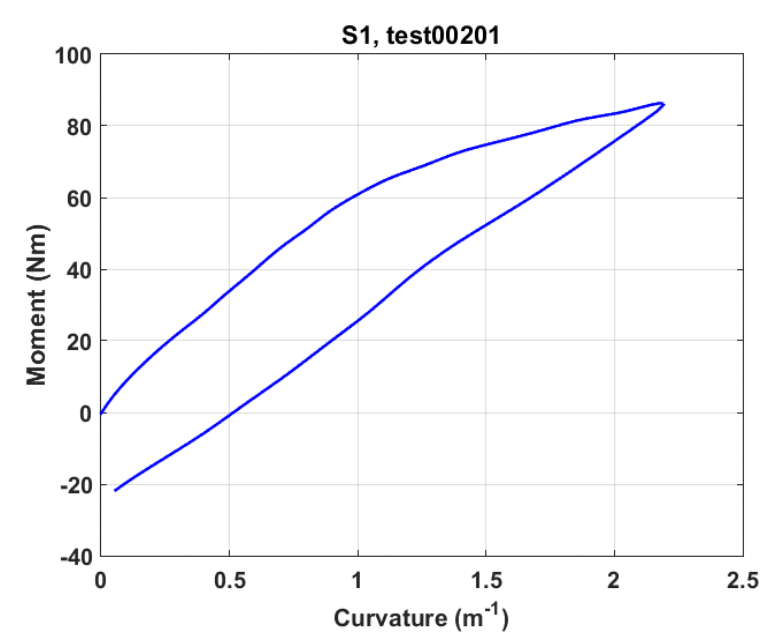

(a)

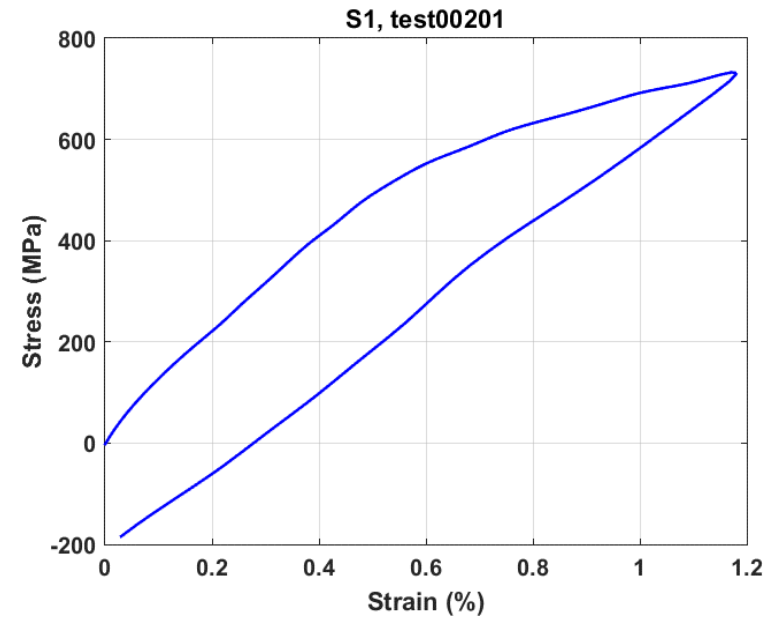

(b)

Figure 5. (a) Moment -curvature curve, and (b) equivalent strain-stress curve for S1 (606C3C).

Specimens S2 and S3 were both tested under static condition for three cycles without any sign of failure. They fractured in follow-up dynamic tests under $\pm 30.48 \mathrm{~N} \cdot \mathrm{m}$ at $5 \mathrm{~Hz}$. The amplitude of applied moment in the dynamic tests was 35 to $36 \%$ of the maximum applied moments used in the respective unidirectional bending process, located in the early second stage of momentcurvature curves. S4 was tested under static conditions for three cycles and fractured during the fourth cycle. Details of these static tests can be found in Appendix A.

A summary of the curvature-moment curves is shown in Figure 6 for the four static tests. The four tests reveal relatively similar elastic behavior.

The failures of the test specimens occurred within the gage sections in all of the tested rods. The majority of the rod fractures involved the PPIs (pellet-to-pellet interfaces). S3 was exceptional in that the fracture location seemed away from pellet-pellet interface, as no end face of the pellet can be identified from the fracture surface of the fuel. 


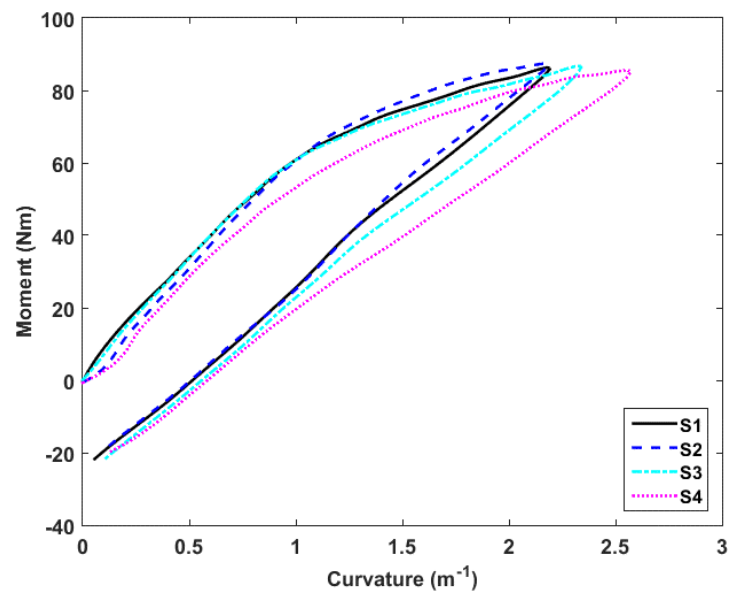

(a)

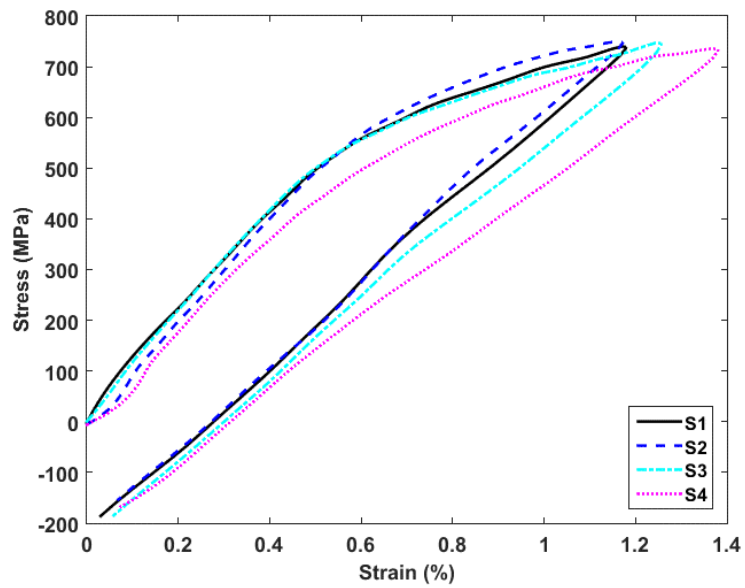

(b)

Figure 6. Curvature-moment curves based on three-LVDT measurements in static tests. (Note: This figure will replace Figure 14 provided in NUREG-7198)

\section{DISCUSSION}

\section{Characteristics of Moment-Curvature Curve}

The responses of the rods are characterized by two linear constituent behavior responses, followed by a nonlinear response during the loading stage and linear unloading stage. If reloaded, the rod would follow the unloading curve and proceed with the nonlinear curve after passing the previous maximum load level.

An effort was made to characterize the moment-curvature response based on the characteristic points to facilitate understanding test results. The flexural rigidities R1, R2, and R3 were obtained, corresponding to the slopes of the first and second linear segments and of the unloading segment, by using curve fitting with the first order polynomial (Figure 7). The characteristic values at the deflection points $A$ and $B$ were then identified. In addition, the moment at point $C$ corresponding to a $0.37 \mathrm{~m}^{-1}$ irreversible curvature, or $0.2 \%$ equivalent plastic strain, was found by using a line with the same slope as that of unloading and horizontal axis intercept $0.37 \mathrm{~m}^{-1}$. The quantities corresponding to points $A, B, C, D$ are designated by $\kappa_{A}, \kappa_{B}$, $\kappa_{C}, \kappa_{D}$, and $M_{A}, M_{B}, M_{C}$, and $M_{D}$. The results are summarized in Table1. For a given specimen, $\mathrm{R} 1, \mathrm{R} 2$, and R3 are generally in decreasing order with a marginal difference between the latter two.

The characteristics derived from equivalent strain-stress curves are provided in Table 2. The E1 in the initial stage of the stress-strain curve was 101 to $125 \mathrm{GPa}$, and the $0.2 \%$ yield strength $\left(\sigma_{\mathrm{C}}\right)$ was 702 to $737 \mathrm{MPa}$. The ranges of the elastic modulus and the $0.2 \%$ yield strength appear consistent with the range of HBU HBR clad. ${ }^{1}$ However, the observation should not be overemphasized, for the results observed here reflect a comprehensive global response of fuel rods with both pellets and cladding included. Moreover, substantial simplifications were made 
with regard to the elasticity and contributions of individual components, where the localized stress riser in clad at the pellet-pellet interface region was not considered.

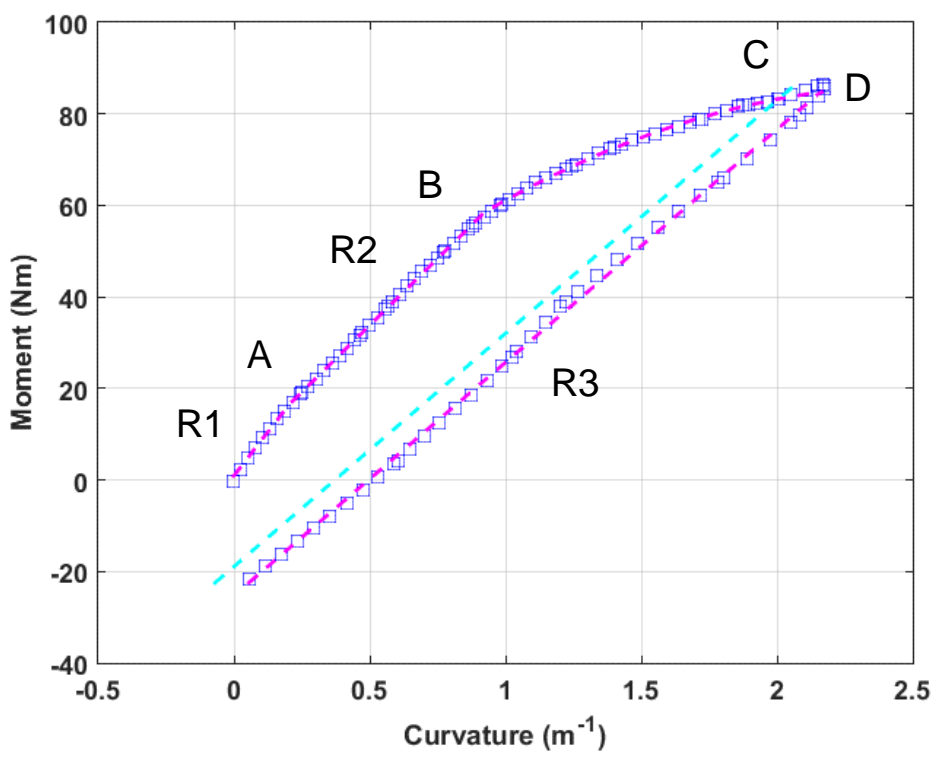

Figure 7. Characteristic points of curvature-moment curve. 
Table 1. Characteristic points and quantities based on curvature-moment curves

\begin{tabular}{|c|c|c|c|c|c|c|c|c|c|c|c|c|}
\hline \multirow{2}{*}{$\begin{array}{l}\text { Spec } \\
\text { label }\end{array}$} & \multirow{2}{*}{ Seg. ID } & R1 & R2 & R3 & $\kappa_{A}$ & $\kappa_{B}$ & $\kappa_{C}$ & $\kappa_{\mathrm{D}}$ & $M_{A}$ & $M_{B}$ & $M_{C}$ & $M_{D}$ \\
\hline & & $\mathrm{N} \cdot \mathrm{m}^{2}$ & $\mathrm{~N} \cdot \mathrm{m}^{2}$ & $\mathrm{~N} \cdot \mathrm{m}^{2}$ & $m^{-1}$ & $\mathrm{~m}^{-1}$ & $\mathrm{~m}^{-1}$ & $\mathrm{~m}^{-1}$ & $\mathbf{N} \cdot \mathbf{m}$ & $\mathbf{N} \cdot \mathbf{m}$ & $\mathbf{N} \cdot \mathbf{m}$ & $\mathbf{N} \cdot \mathbf{m}$ \\
\hline S1 & $606 C 3 C$ & 78.655 & 57.33 & 51.027 & 0.202 & 0.968 & 2.009 & 2.166 & 16.695 & 60.599 & 83.595 & 85.413 \\
\hline $\mathrm{S} 2$ & 605D1E & 73.016 & 60.848 & 52.699 & 0.32 & 1.009 & 2.001 & 2.154 & 20.18 & 62.133 & 85.914 & 87.294 \\
\hline S3 & 609C5 & 71.517 & 59.369 & 47.101 & 0.311 & 0.933 & 2.149 & 2.308 & 22.338 & 59.288 & 83.728 & 85.235 \\
\hline S4 & 609C6 & 63.117 & 54.849 & 41.704 & 0.503 & 0.862 & 2.329 & 2.507 & 28.54 & 48.244 & 81.656 & 85.02 \\
\hline
\end{tabular}

(Note: This table will replace Table 4 in NUREG-7198.

Table 2. Characteristic points and quantities based on equivalent strain-stress curves

\begin{tabular}{|c|c|c|c|c|c|c|c|c|c|c|c|c|}
\hline \multirow{2}{*}{$\begin{array}{l}\text { Spec } \\
\text { label }\end{array}$} & \multirow{2}{*}{ Seg. ID } & E1 & E2 & E3 & $\varepsilon_{A}$ & $\varepsilon_{\mathrm{B}}$ & $\varepsilon_{C}$ & $\varepsilon_{D}$ & $\sigma_{A}$ & $\sigma_{\mathrm{B}}$ & $\sigma_{\mathrm{C}}$ & $\sigma_{\mathrm{D}}$ \\
\hline & & GPa & GPa & GPa & $\%$ & $\%$ & $\%$ & $\%$ & $\mathrm{MPa}$ & $\mathrm{MPa}$ & $\mathrm{MPa}$ & $\mathrm{MPa}$ \\
\hline S1 & $606 C 3 C$ & 125.337 & 91.355 & 81.312 & 0.109 & 0.521 & 1.081 & 1.166 & 143.13 & 519.514 & 716.662 & 732.246 \\
\hline $\mathrm{S} 2$ & 605D1E & 116.704 & 97.255 & 84.23 & 0.172 & 0.542 & 1.075 & 1.157 & 173.206 & 533.284 & 737.397 & 749.247 \\
\hline S3 & $609 C 5$ & 114.654 & 95.178 & 75.511 & 0.167 & 0.501 & 1.154 & 1.239 & 192.306 & 510.412 & 720.813 & 733.788 \\
\hline S4 & 609C6 & 101.069 & 87.83 & 66.781 & 0.27 & 0.463 & 1.251 & 1.346 & 245.417 & 414.854 & 702.162 & 731.089 \\
\hline
\end{tabular}

(Note: This table will replace Table 5 in NUREG-7198. 


\section{ACKNOWLEDGEMENT}

This research was sponsored by jointly funded by the Fuel Qualification Program of the US Department of Energy and Nuclear Reactor Research of U.S. Nuclear Regulatory Commission, and was carried out at Oak Ridge National Laboratory under contract DE-AC05-00OR22725 with UT-Battelle, LLC.

\section{REFERENCE}

1 R.S. Daum, S. Majundar, and M. C. Billone, Experimental and analytical investigation of the mechanical behavior of high-burnup Zircaloy-4 fuel cladding, J. ASTM Internal, 5, Paper ID JAI101209. 